\title{
Determinants of Electricity Consumption and Volatility-Driven Innovative Roadmaps to One Hundred Percent Renewables for Top Consuming Nations in Africa
}

\author{
Mark Agyei-Sakyi *(D), Yunfei Shao *, Oppong Amos (D) and Armah Marymargaret \\ School of Management and Economics, University of Electronic Science and Technology of China, \\ Chengdu 611731, China; Oppong.amos@gmail.com (O.A.); Armahmarymargaret@gmail.com (A.M.) \\ * Correspondence: maccc2@yahoo.com (M.A.-S.); shaoyf@uestc.edu.cn (Y.S.)
}

Citation: Agyei-Sakyi, M.; Shao, Y.; Amos, O.; Marymargaret, A. Determinants of Electricity Consumption and Volatility-Driven Innovative Roadmaps to One Hundred Percent Renewables for Top Consuming Nations in Africa. Sustainability 2021, 13, 6239. https:// doi.org/10.3390/su13116239

Academic Editors: Ali Khosravi, Mohammad Malekan and Juan Jose Garcia Pabon

Received: 20 April 2021

Accepted: 24 May 2021

Published: 1 June 2021

Publisher's Note: MDPI stays neutral with regard to jurisdictional claims in published maps and institutional affiliations.

Copyright: (c) 2021 by the authors. Licensee MDPI, Basel, Switzerland. This article is an open access article distributed under the terms and conditions of the Creative Commons Attribution (CC BY) license (https:// creativecommons.org/licenses/by/ $4.0 /)$.

\begin{abstract}
The determinants of providing affordable electricity for all in top energy-consuming African countries vary and are in line with the percentage of the current population with access to electricity and volatility in a country's electric power system, but there is rare evidence of such research. This study categorizes Egypt-Algeria as a panel of countries with $100 \%$ access to electricity, and Nigeria-South Africa as otherwise, to investigate the causal relationship between domestic electricity demand, renewable electricity generation, population, and GDP. The study proposed and implemented a novel machine learning model for viable and volatility-driven pathways for renewable electric power transition up to 2030. Results from Pedroni cointegration analysis suggest no evidence of long-run relationships among the variables. Nonetheless, there exists a short-run unidirectional causal relationship from GDP to electricity consumption for Nigeria-South Africa; all except Egypt can achieve $100 \%$ access to green electricity. The implication is that, through radical renewable electricity generation innovations, countries can achieve renewable-dominated electric power systems despite expected disruptions from the coronavirus pandemic. For sustainable energy planning, countries aiming to achieve $100 \%$ renewables is possible due to the radical transition pathways since it takes into account the volatility.
\end{abstract}

Keywords: electricity consumption; electricity generation; renewables; volatilities; Bi-LSTM; covid-19 pandemic; sustainable electric-power innovations

\section{Introduction}

Electricity plays a key role in the economic development of countries [1-4]. Access to electricity propels the economy by providing economic units, including individuals, households, firms, and the government, with the electric power required in performing or engaging in income-generating activities and value-added services [5,6]. Providing electricity for domestic consumption increases the percentage of the total population with access to electric power improves well-being [7] and propels the economy to greater heights [8,9]. If users utilize the electricity supplied for income-generating and economic activities, domestic electricity consumption could contribute to national output, which undeniably adds to economic growth. On the premise that electricity is primarily generated for consumption or exports, it is laudable to relate electricity consumption with total generation (i.e., from renewable and non-renewable sources), a total number of people to use the electric power generated (often proxied with population), and economic activities (which can be proxied with the gross domestic product). Africa is among the continents with a significant fraction of countries in the region with high proportion of the population with no to little access to electricity [6]. As part of the efforts towards achieving Sustainable Development Goal 7 (SDG7) of which access to electricity is essential, energy policymakers across countries in the African region have recorded significant increase in the fraction of the total population with access to electricity. For instance, access to electricity (as 
percentage of total population) for Sub-Saharan Africa increased from $26.02 \%$ in 2000 to $47.67 \%$ in 2018 [7].

Africa is among the continents with a significant proportion of countries in the region with a high proportion of the population with no to little access to electricity. As part of the efforts towards achieving Sustainable Development Goal 7 (SDG7) of which access to electricity is pivotal, decision-makers across countries in the African region have recorded significant increase in the fraction of the total population with access to electricity. For instance, access to electricity (as a percentage of a total population) for Sub-Saharan Africa increased from $26.02 \%$ in 2000 to $47.67 \%$ in 2018 [10]. The coronavirus pandemic and disruptions it has caused, and is still causing, to the economic system have raised doubts among researchers that the observed (average) year-on-year increase in the provision of electricity will be distorted because decision-makers may focus on economic growth to steer the coronavirus-stricken economies [7,11]. Though countries in the African region are recording a significant progress in electricity provision, the electricity generation capacity varies widely across countries and has caused variation in electricity access in the preCovid-19 era, and it is expected to alter transformations in the electric power sector in the post-Covid-19 era. In 2018, Egypt, Algeria, Nigeria, and South Africa were classified as the top four electric power generating and consuming nations in Africa [12]. Enerdata reports in the Global Statistical Yearbook 2020 [12] that, in 2019, Egypt, Algeria, Nigeria, and South Africa jointly contributed $\sim 66 \%$ of the $\sim 858$ TWh of total electric power generation and $\sim 67 \%$ of the 692 TWh of domestic electric power consumption. Out of the four countries, Egypt and Algeria achieved $100 \%$ access to electricity as of the referenced year. In the same 2018 economic year, Nigeria and South Africa supplied electricity to $~ 57 \%$ and $91 \%$ of the total population [13]. The variation in electricity access levels recorded in each of the four-top electric-power-consuming countries is expected to reflect in their policymaking towards transforming the electric power sector to renewable-dominant systems. All else being equal, policymakers in Egypt and Algeria are bothered with renewable electric power transition-related challenges, but leaders in Nigeria and South Africa must figure out how to provide electricity for all, in addition to the transitioning-related policymaking challenges.

It is worth noting that not only are there variations in access to electricity but the electricity mixes, as well. Though there exist vast differences in access to electricity indicators, all top four countries supplied less than a quarter of electric power from renewable sources in 2019. The percentage contribution from solar, wind, geothermal, and hydro (herein referred to as renewables) to total electric power production in 2019 was $0.93 \%$ for Algeria, $10 \%$ for Egypt, $20.32 \%$ for Nigeria, and $6.46 \%$ for South Africa [12]. The low contribution of renewables means that all four countries need to implement radical renewable electric power innovations both in generation and utilization perspectives to steer the selected nations on viable pathways to achieving SDG7.

To minimize the negative domino effects of fulfilling electricity demand and transforming the electric power sector via radical renewable electric power innovations in the post-Covid-19 pandemic era, there is the need to unearth the dynamic causal linkages between domestic electricity consumption and innovation-driven renewable electric power supply, national economic output, and total population. Though recent studies, including those by Bohlmann and Inglesi-Lotz [14], Kayalica et al. [15], Kim [16], Kostakis [17], and Đurišić et al. [18], have assessed the linkages between selected macro- and macroeconomic indicators and electricity consumption, no scientific work, to our knowledge, has investigated the impact of radical innovation-driven renewable electric power supply, national output, and total population on domestic electricity demand for top power-generating nations in Africa.

In addition to understanding the causal linkages, the unforeseen consequences from implementing radical green electric power innovations, estimates of contributions from renewables itself, and determinants of domestic electric power consumption would be instrumental in the drafting of feasible policies that could make the transition sustain- 
able in the four countries. In terms of policymaking, the benefits from estimating the shocks in renewable electric power generation, reactions, and contributions are vast, but a critical review of existing the literature finds no evidence of such works, to the best of our knowledge.

With prior knowledge of the nature of the causal linkages and estimates of renewable electricity supply shocks, decision-makers leverage transition pathways proposed by modelers and researchers for workable policymaking. Several renewable energy and electricity transition pathways but the failure to capture the increased year-on-year volatility in the electric power system [19] has rendered existing transition pathways unreliable, ambiguous and irrelevant [20]. The coronavirus pandemic has slowed economic activities [21] and shut down several profit-making organizations but increased household electricity demand due to lockdowns. The coronavirus-induced havoc and disruptions caused in electricity demand have increased further the volatility in the electric power systems that researchers now question whether the countries can recover and still achieve the SDGs [11,22,23]. Such volatility is expected to increase in the post-Covid-19 era as policy-makers would seek to implement radical policies to provide electricity to the population without jeopardizing the SGD7 targets. Works that inculcate year-on-year volatility in renewable electric power systems in each of the top four electricity-consuming African countries would contribute to outputting reliable, representative, and relevant roadmaps; however, such works are very rare for Egypt, Algeria, Nigeria, and South Africa.

The research gaps identify above pose to research questions that must be answered. The questions are as follows: What are the determinants of domestic electric power consumption amidst radical renewable innovations if access to electricity is considered? How high or low is volatility in electric power systems and to what extent does it affect renewable electric power transition pathways? This study contributes to answering the two research questions; thus, the following research objectives are set. First, it leverages the variations in access to electricity power to investigate the determinants of domestic electric power consumption for top electric power consuming nations in Africa. Second, the study quantifies the volatility in the electric power system of each of the four sampled countries, and utilizes the observed unpredictability to propose volatility-consistent renewable electric power transition pathways.

This study entails three novelties that contribute to bridging the research gaps discussed earlier. First, the study categorized Egypt and Algeria into a panel of top electricpower-generating African countries that have achieved 100\% access to electricity, and Nigeria and South Africa as a panel of top electric power generating African countries to achieve $100 \%$ access to electricity, for causality analysis. The corresponding two panels were utilized to investigate the causal relationship between total domestic electric power consumption, radical renewable electric power generation, national output, and total population. Second, this study proposed and applied variance decomposition analysis to estimate the contributions of domestic electric power consumption, national output, and total population required to achieve targeted shocks in renewable electric power generation for Egypt-Algeria, as well as Nigeria-South Africa panels. Third, the study adopted the volatility metric proposed by Sherwin, Henrion, and Azevedo [19] to estimate historical year-on-year volatility in renewable electric power generation for each of the top four countries (i.e., Egypt, Algeria, Nigeria, and South Africa). Three versions (i.e., minimum, average, and maximum) of the observed positive volatilities were used to compute the volatility-driven renewable electric power generation outlook for each of the four countries for 2025 and 2030. The volatility-driven outlook could be instrumental in proposing reliable, representative, relevant, and sustainable roadmaps towards achieving $100 \%$ access to renewable and affordable electric power.

The rest of the study is covered in three sections. In the Sections 2 and 3, we review recent relevant works in the literature on the subject and provide vivid details of the methods and materials utilized and/or proposed in this research, respectively. The empirical 
results derived from the methods and materials are captured in Section 4. Section 5 provide a summary of findings and conclusions drawn from the study.

\section{Literature Review}

\subsection{Antecedents of Sustainable Development}

In this work, recent evidence indicates that global warming is at a tipping point [24]. Essentially, less attention in the distant future means possible global damage caused will be irreversible [25]. Again, global current energy and electric power systems are not sustainable as a result of the heavy dependence on fossil fuels (coal, oil, and natural gas) for which the deposits and reserves are depleting and could be blank [26]. In addition, this coal, oil, and natural gas are not sustainable [27]. Furthermore, the economic recovery from the Covid-19 global pandemic has caused policy-makers in countries to plan for economic sustainable plans [28]. As a result, there is a need to improve human health and psychological well-being. The ultimate solution for global warming is to mitigate greenhouse gas emissions [11]. Greenhouse gases are among the leading factors of global warming. Abundant of solar, wind, and geothermal energy can resolve the problem of burning fuels pollutants such as carbon monoxide, Sulphur oxides, Oxones, and nitrogen oxides released from fossil fuels. In addition, for economic recovery programs from the Covid-19 pandemic, the need for optimal and sustainable policy planning for human health, improving the living standards and well-being of the society, is the ultimate aim of policy-makers [29]. Among these four challenges and solutions, renewable electric power generation and consumption play a key role and are depicted in Figure 1.

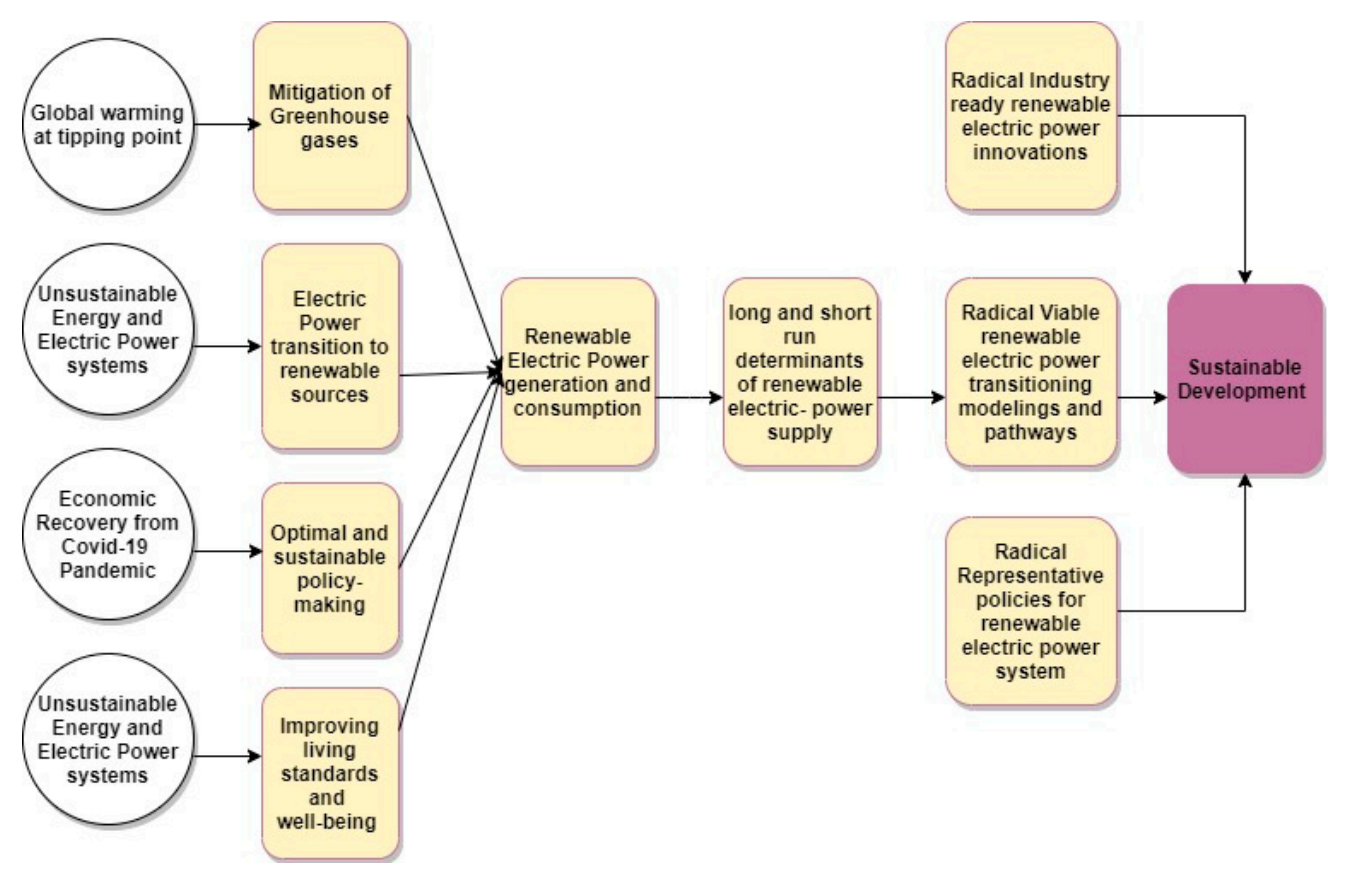

Figure 1. Global warming and sustainable development planning.

The adoption of renewables does not cause the greenhouse gas that causes climate change. In addition, transitioning to renewable electric power play a key role in the electric transition power system. Optimal and sustainable policymaking requires the need to provide energy for all the policies [29]. Energy is central for human life and production services for companies. At the household level, access to undistracted electric power improve human well-being. For the four countries to be able to transition to renewables electric power generation consumption requires the need to determine the long- and shortrun determinants that are supposed to transition to renewable electric power innovations to fasten the renewable electric power system [30]. 
Furthermore, radical viable renewable electric power needs transitioning and pathway models that handle the viabilities of the pathways. Radical policies from policy-makers for renewable electric power systems varied among the four countries [31]. The need for radical policies is in line to combat climate change, the radical aproach should be representative of the four countries aiming at transitioning to renewable electric power system by considering long and short-run determinants, essentially proposing pathways that are practical and implementing innovations that is industry-ready. Policies that are representative of each country will enable each country to achieve sustainable development [32]. By 2030, all countries will have renewable electric power systems that are sustainable and uninterrupted [7], which will eventually lead to slow the pace of or fix global warming. Hence, it can lead to the sustainability of energy recovery programs from the coronavirus to be effective and improve human well-being. There is a need for proven antecedents to be viable calls for policies among countries. Some of the policies are proposed in line with each country's INDCs, particularly those relating to renewable energy. Some progress made from the implementation of renewable electrical energy policies is discussed below.

\subsection{Recent Developments on Renewable Electric Power Policies of Selected Countries}

The four countries are among the nations that signed the Paris Agreement and have submitted their Intended Nationally Determined Contributions (INDCs) [33]. Due to the heavy reliance on fossil fuel in existing electric power systems, energy policies geared towards transforming the power sectors are among the key considerations in the roadmaps of each of Egypt, Algeria, Nigeria, and South Africa [34]. It can be observed that a greater proportion of the transformations specified in the INDCs of the four countries entail a quick and sustainable transition to electricity generation from renewables. Some developments in Egypt and Nigeria are discussed below. Egypt has confirmed that, as part of its strategies to achieve the INDCs, the country will support technological development and research to propose industry-ready technologies to help the nation build sustainable electric power systems to aid the sector deal properly with climate change [35].

As a result, new models and designs are being proposed by researchers. For instance, the authors of Reference [36] have proposed an autonomous optimization model based on multiple objectives and wedges for the optimal design of hybrid microgrid energy systems (HMGEs) in a community area in Egypt, in which the authors showed that any money invested in the technology can be recovered after 3.4 years. A two-way proposal of a step-by-step approach to ensure the efficient planning and design of a hybrid renewableenergy-based microgrid (HRE-MG) for the urban community in Egypt [25]. Based on the expected impacts of such research works and other considerations, Egypt targets to generate $20 \%$ of electricity from renewable sources by 2022 and pursue measures to increase it to $42 \%$ by 2035 [37]. As reported [29], the country has set technology-specific targets that include plans to increase generation from solar PV to $0.7 \mathrm{GW}$ by 2027, wind to $7.2 \mathrm{GW}$ by 2020 , concentrating solar thermal power (CSP) to $2.8 \mathrm{GW}$ by 2030 , and hydropower to $2.8 \mathrm{GW}$ by 2020 [26]. It must be noted that radical innovations, investment, and consistent and coordinated efforts among all stakeholders in the electric power system are prerequisites to achieving the set targets.

For Nigeria, the country plans to increase access to energy to $90 \%$ and access to electricity to $100 \%$ by 2030 . As part of the efforts to increase the share of renewables in the energy mix, the country plans to work towards providing $13 \mathrm{GW}$ of power from off-grid solar PV by 2030 as stipulated in their INDCs [38]. The 13 GW off-grid electricity is expected to impact access to electric power in rural areas to improve their standard of living [34]. Evidence from a recent choice experiment performed shows that sampled rural folks and households (despite their low levels of income) are willing to switch to off-grid power in as much as the high fees users pay commensurate with high quality, efficient, and stable electricity supply. Such development could be one of the key ancillary provisions required to transform the electric power sector. The policies of increasing the share of renewables in total electric power generation are expected to contribute massively to a 
reduction in emissions by 2030 [39]. Due to the expected increase in renewable sources, the Nigerian government estimates that more than half of 2030 emission reductions are expected from electricity generation. Other targets include improving the electricity grid, promoting climate-smart agriculture, and improving energy efficiency by $2 \%$ per year through to 2030 [38].

To achieve the research objectives, several methodological procedures were adopted, proposed, and utilized.

\section{Materials and Methods}

\subsection{Materials and Sources of Data}

Four countries in Africa, namely Egypt, Algeria, Nigeria, and South Africa, were selected. The selection criteria utilized is the weight of the country's electric power system, proxied with total domestic electric power consumption and total electricity generation, in total electricity consumption in Africa. Thus, the four countries generated and consumed the majority of electric power in Africa, as depicted by the recently available report published by Enerdata [12]. The fourtop electric-power-consuming nations were further grouped into two panels: one panel comprising Egypt and Algeria for countries that have achieved the target of providing $100 \%$ access to electricity to all indigenes as of 2019, and another panel for countries (i.e., Nigeria and South Africa) that are yet to achieve the 100\% access to electricity target. To investigate the role of demography, economic output, and renewables in achieving $100 \%$ access to electric power, the study selected total domestic electric power consumption (ELC) as a proxy for $100 \%$ access to electric power demand; renewable electric power generation from solar, wind, geothermal, and hydro as a proxy for total renewable electric power generation (RELG); total population (TP) as a proxy for a country's demography; and gross domestic product (GDP) as a proxy for national economic output. ELC and RELG are measured in TWh, and TP and GDP are measured in million people and purchasing power parity constant 2017 international dollars, respectively. The study utilizes annual data covering 1990-2019 on ELC and RELG extracted from Enerdata's Global Statistical Yearbook 2020, and TP and GDP from World Bank's World Development Indicators (2020). The dataset was deposited in Mendeley Data repository, and it is available at Agyei-Sakyi [40]. The basic associations between and among ELC, RELG, TP, and GDP from utilizing the annual data of the four sampled countries are depicted in Figure 2.

From Figure 2, there exist statistically significant linear associations among the study variables. Notwithstanding, the significant associations, the low contribution, and inconsistency in the supply of renewable electric power in the four countries have pushed the basic relationship between ELC and RELG, RELG and TP, and RELG and GDP to cubic forms.

\subsection{Methods}

In order to achieve the research objectives, a number of methodological procedures were adopted, proposed and utilized. A schematic structure of the methods and materials are depicted in Figure 3. 


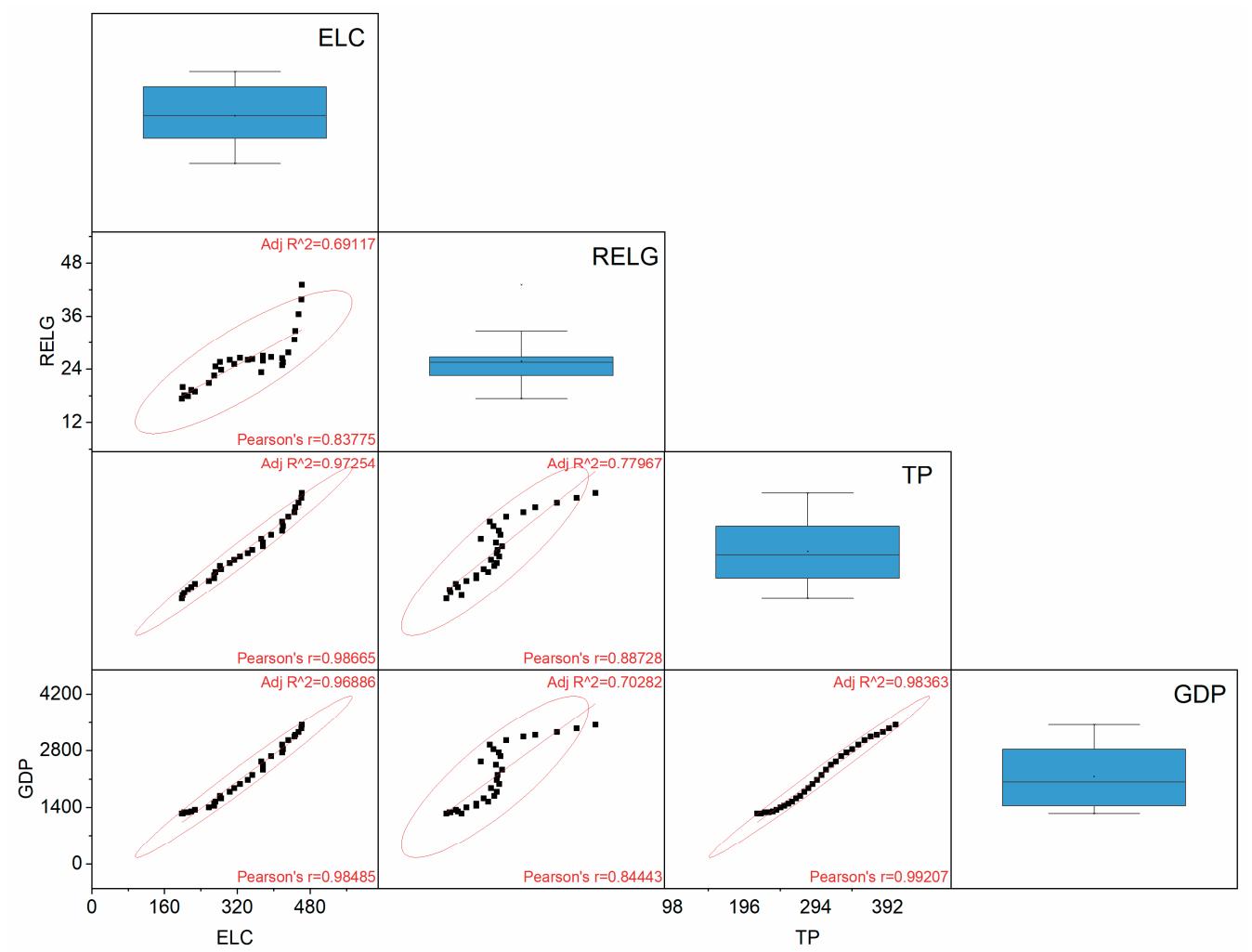

Figure 2. Scatter metrics of basic associations and summary statistics of selected variables.

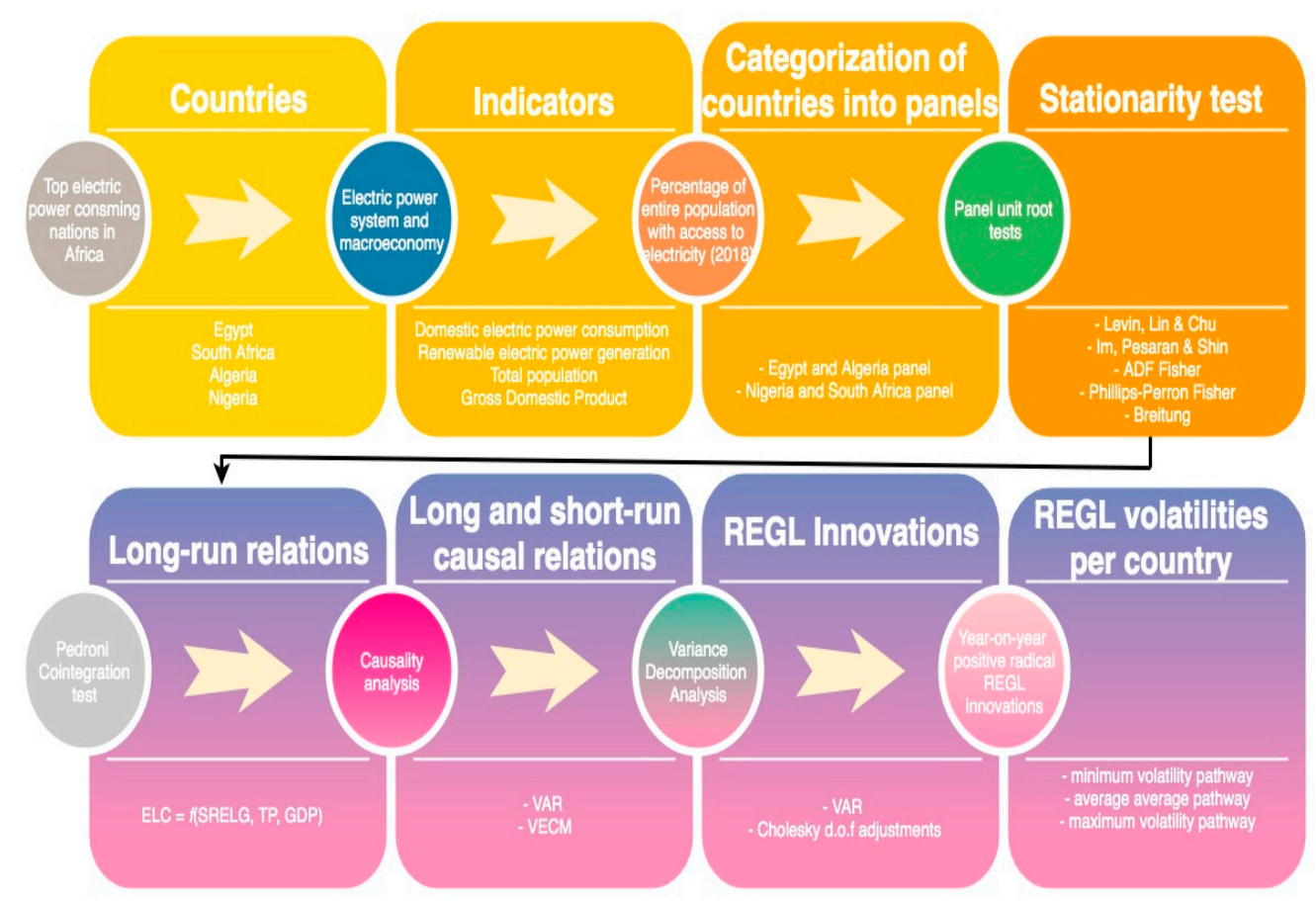

Figure 3. A schematic structure of various methods and materials.

\subsubsection{Econometric Relational Models}

The general relational model for the four variables is specified as follows:

$$
E L C_{i t}=f\left(R E L G_{i t}, T P_{i t}, G D P_{i t}\right)
$$

where $i$ is panel and $t$ is time. 
The relatively low Pearson's correlation coefficients between RELG and ELC, TP, and GDP depicted in Figure 3 can be ascribed to the nonlinearity and inconsistency observed in RELG. Studies on threshold analysis, including those by Valadkhani and Bowden [41], Brecha [42], and Lin and Li [43], show that, if the volume of renewables does not reach certain thresholds in the electric power generation mix, the observed low RELG is likely not to have a significant impact (i.e., causation) on total domestic electric power consumption. Considering the low contribution of renewables to total electricity generation in the four countries in 2019 (i.e., $0.93 \%$ for Algeria, 10\% for Egypt, 20.32\% for Nigeria, and 6.46\% for South Africa; see Enerdata [12]), increasing RELG in the selected countries by the exorbitant margins require radical innovations both in electric power generation and utilization. This study captures such radical innovation in renewable electric power generation by squaring the historical RELG levels (i.e., $R E L G^{2}$ ); the resultant radical innovation-induced variable is designated as SRELG. The corresponding extended general model is specified as follows:

$$
E L C_{i t}=f\left(S R E L G_{i t}, T P_{i t}, G D P_{i t}\right)
$$

A series of econometric techniques, including panel unit root and stationarity test, cointegration, and causality analysis, were performed. The natural log form (i.e., $\ln$ ) of Equation (2) was utilized to transform the function into linear form. The natural log form is then expressed as follows:

$$
\ln E L C_{i t}=f\left(\ln S R E L G_{i t}, \operatorname{lnT} P_{i t}, \ln G D P_{i t}\right)
$$

\subsubsection{Panel Unit Root and Stationarity}

Econometric methodologies for performing panel causal relational analysis require the series-herein ELC, SRELG, TP, and GDP — to be stationary either at level (i.e., I(0)) or firstorder (i.e., I(1)) of integration [44]. Several unit root test technologies have been proposed and this study leverage the wide utilization and adopts the Levin, Lin, and Chu [45]; Pesaran and Shin [46]; Augmented Dickey-Fuller/Fisher [47,48]; Phillips-Perron/Fisher [49]; and Breitung [50] tests to test for stationarity in the four series. Following the works by Wang et al. [51], Oppong et al. [52], and Agyeman et al. [53], this study specifies the general equation for the unit root as follows:

$$
\Delta y_{i t}=\alpha y_{i t-1} \sum_{j=1}^{p i} \beta_{i j} \Delta_{i t-j}+X_{i t}^{\prime} \delta+\varepsilon_{i t}
$$

where $i=1,2, N$ denotes the number of time points $t$; and $X_{i t}$ signifies exogenous variables. Based on its widespread adoption, the Akaike Information Criterion (AIC) was used to select the optimal lags required for testing for stationarity in the series.

The output from adopting the five-unit root test technologies reports 18 statistics (both for $I(0)$ and $I(1)$ ), and the statistical significance of at least one, either at $5 \%$ or $1 \%$ level of significance at level or first difference, is used in concluding on the nature of unit root. The significance of at least one metric is used to reject the null hypothesis that the series is not stationary.

\subsubsection{Panel Cointegration Analysis}

Panel cointegration models were employed on the stationary series to investigate the existence of a long-run relationship between domestic electric power demand and the independent variables. A careful review of the existing literature finds several tests for panel-related investigations but the Pedroni [54,55] test technology has been widely adopted. Based on its wider acceptance and adoption, this study adopts the Pedroni 
test technology to explore the cointegrating relationships between and among the study variables. The general model for cointegrating relationship is specified as follows:

$$
y_{i t}=\alpha_{i}+\lambda_{i t}+\sum_{j=1}^{m} \beta_{j i} x_{j i t}+\varepsilon_{i t}
$$

where $t, m$, and $x$ represent time, lag structure, and the number of regressors, respectively. The automatic AIC was utilized to select a lag length.

The null hypothesis of the cointegration test is that there is no long-run relationship between the dependent and independent variables in a given model. To test whether to reject the null hypothesis, the residuals from Equation (5) are used to estimate the residual regression:

$$
e_{i t}=\rho_{i} e_{i t-1}+\mu_{i t}
$$

From Equation (6), the null hypothesis of cointegrating relationship is as follows:

$$
H_{0}: \rho_{i}=1 ; \forall_{\mathrm{i}} ;
$$

and alternate of least one cointegrating relationship as follows:

$$
H_{1}: \rho_{i}<1 ; \forall_{\mathrm{i}}
$$

The Pedroni test of cointegration outputs eight statistics for common AR coefficients within-dimension, and three statistics for common AR coefficients between-dimension. The statistical significance at $5 \%$ or $1 \%$ level of at least six statistics out of the possible eleven is used as a decision criterion to reject the null hypothesis of no long-run relationship existing between the dependent and independent variables.

\subsubsection{Panel Causal Relationships}

Results from Equations (5) and (6) are used to draw a maximum of two conclusions, i.e., the existence of a cointegrating relationship or otherwise. One limitation of cointegration results is that it fails to capture the causal linkages of the individual independent variables in a given model. It is expected that cointegrated models have within them at least one long-run and/or one short-run causal relationship. The study adopts the vector error correction model (VECM) [56] environment to test for the existence of long- and short-run causalities in cointegrated models. The empirical VECM model is specified as follows:

$$
\begin{aligned}
\Delta \ln E L C_{i t}= & \alpha_{1 i}+\beta_{1 i} e c t_{i t-1}+\sum_{i=1}^{l} \alpha_{11 i t} \Delta \ln E L C_{i t-1}+\sum_{i=1}^{l} \alpha_{12 i t} \Delta \ln S R E L G_{i t-1}+ \\
& \sum_{i=1}^{l} \alpha_{13 i t} \Delta \ln T P_{i t-1}+\sum_{i=1}^{l} \alpha_{14 i t} \Delta \ln G D P_{i t-1}+\mu_{1 i t}
\end{aligned}
$$

where $e c t_{i t-1}=$ error-correction term, $\Delta=$ first difference, $\alpha_{n i}=$ constant term, $\beta_{n i}=$ parameters for the ect and measures the speed of adjustment, $\alpha_{n i t}=$ coefficients for the regressors, $l=$ maximum lag length, and $\mu_{\text {nit }}=$ serially uncorrelated error term.

To minimize the problem of adding too many or few lags (i.e., issues relating to degrees of freedom-d.o.f.), the maximum lag selection was restricted to the cube root of the sample size per country, i.e., at most, 3 out of which the study selects 2 . The lags of 2 signify that each variable has at least two representations in a given causal model. Though the statistical significance of any of the lagged values of a given variable could be interpreted as the existence of a causal relationship running from the variable in question to the dependent variable in the relational model being tested, this study uses the statistical significance (at $5 \%$ or $1 \%$ level) of the joint lags to a conclusion on the nature of causal linkage. The Wald test technology is adopted to compute Chi-square statistics to test for the joint statistical significance of representations of a variable in a given model. The statistical significance of the Chi-square statistic is interpreted as the existence of a causal relationship running from a given independent variable to the dependent variable of the model. 
Unlike cointegrated models, models that do not depict cointegrating relationships can only have short-run causal relations within them. To test for possible short-run causal relations in non-cointegrating models, the vector autoregression model (VAR) [57] model is utilized and the empirical model used to determine corresponding causalities is specified as follows:

$$
\ln E L C_{j t}=y_{1 j}+\sum_{i=1}^{l} y_{11 j t} \ln E L C_{j t-j}+\sum_{i=1}^{l} y_{12 j t} \ln S R E L G_{j t-j}+\sum_{i=1}^{l} y_{13 j t} \ln T P_{j t-j}+\sum_{i=1}^{l} y_{14 j t} \ln G D P_{j t-j}+\in_{1 j t}
$$

where $\gamma_{n j}=$ constant term, $\gamma_{n j t}=$ coefficients of the independent variables, $l=$ lag length, and $\epsilon_{n j t}=$ stochastic term. It must be noted that the VAR model loses 1 d.o.f, hence, maximum lag of 2 used in VECM models decreases to 1 in the test for short-run causal relationships.

\subsubsection{Renewable Electric Power Innovations and Decomposition}

As stated earlier, the $\sim 9$ years remaining to achieve the target of providing clean and affordable electricity to $100 \%$ of the population by 2030 (i.e., SDG7) require radical innovations in renewable electric power generations, distribution, and utilization. These radical innovations and are expected to shock the electric power system and this study performs variance decomposition analysis (VDA) [58] to estimate the contributions of each variable in achieving a given radical renewable electric power innovation. The timeline of data used in the study covers 1990-2019, leaving 11 years to reach 2030. To estimate future REGL innovations, this study performs VDA on InSREGL from a VAR environment for 11 periods via Cholesky decomposition technology with Monte Carlo standard errors from 100 repetitions.

\subsubsection{Renewable Electric Power Volatility Estimation and Power Transition Pathways}

Noting that the four sampled countries have made some strides in increasing the share of renewables in total electricity generation, and radical innovations are required to quicken the transitioning to $100 \%$ renewables, a metric that measures the year-on-year volatility in renewable electric power supply and utilizes the observed volatilities via own-data-driven approaches [59] in estimating future supply levels is desirable. This study adopts and extends the volatility metric proposed by Sherwin, Henrion, and Azevedo [19] and estimates the year-on-year volatility in renewable electric power supply as follows:

$$
\Delta R E G L_{k t}=\left[R E G L_{k t}-R E G L_{k(\mathrm{t}-1)}\right] / R E G L_{k(\mathrm{t}-1)}
$$

where $\Delta$ is growth, $k$ is country, and $t$ is the year. This study ignores the absolution of the denominator in Equation (9) as proposed by Sherwin, Henrion, and Azevedo [19] because the observed historical trends in REGL show that each of the four countries supplied a fraction of the national electric power demand from renewables domestically, hence no negative REGL values were recorded in the Global Statistical Yearbook 2020.

Based on the historical non-negative REGL trends, three possible solutions from Equation (9) are expected, i.e., $\triangle R E G L_{k t}=0, \Delta R E G L_{k t}<0$, or $\Delta R E G L_{k t}>0$. Out of the three possibilities, only in $\triangle R E G L_{k t}>0$ represent solutions in which a country's innovative REGL policies increased year-on-year generation of electric power from renewable of did the countries. On the basis that radical and consistent growth in REGL is desirable to facilitate the transition to a $100 \%$ renewable electric power system, the study leverages on $\triangle R E G L_{k t}>0$ solution for further future analysis. The set of $\triangle R E G L_{k t}>0$ series is used to compute three summary statistics namely minimum, average, and maximum volatilities. We then use each three summary statistics to compute the corresponding future value of REGL for three paths assuming that the growth works in a consistent year-on-year increment form. The compounding nature of year-on-year REGL required is in line with consistency in green electricity supply necessary to avert the consequences of unsustainable fossil fuel-driven electric power systems. In performing a further analysis, two future (i.e., 2025 and 2030) volatility-induced REGL targets were computed. 


\subsection{The Bi-LSTM with Two-Staged Attention Machine Learning Model}

This study proposes a machine learning model with a two-stage deep attention neural network that combines densely connected bidirectional a long short-term memory and attention mechanisms for each stage [60], for volatility-driven roadmaps. The machine learning modeling approach is proposed due to its power to predict nonlinear as well as volatile trends. The architecture of the proposed model involves an input layer, embedding layer, a long short-term memory layer, attention layer, and output layer. The structure of the architecture is captured in Figure 4.

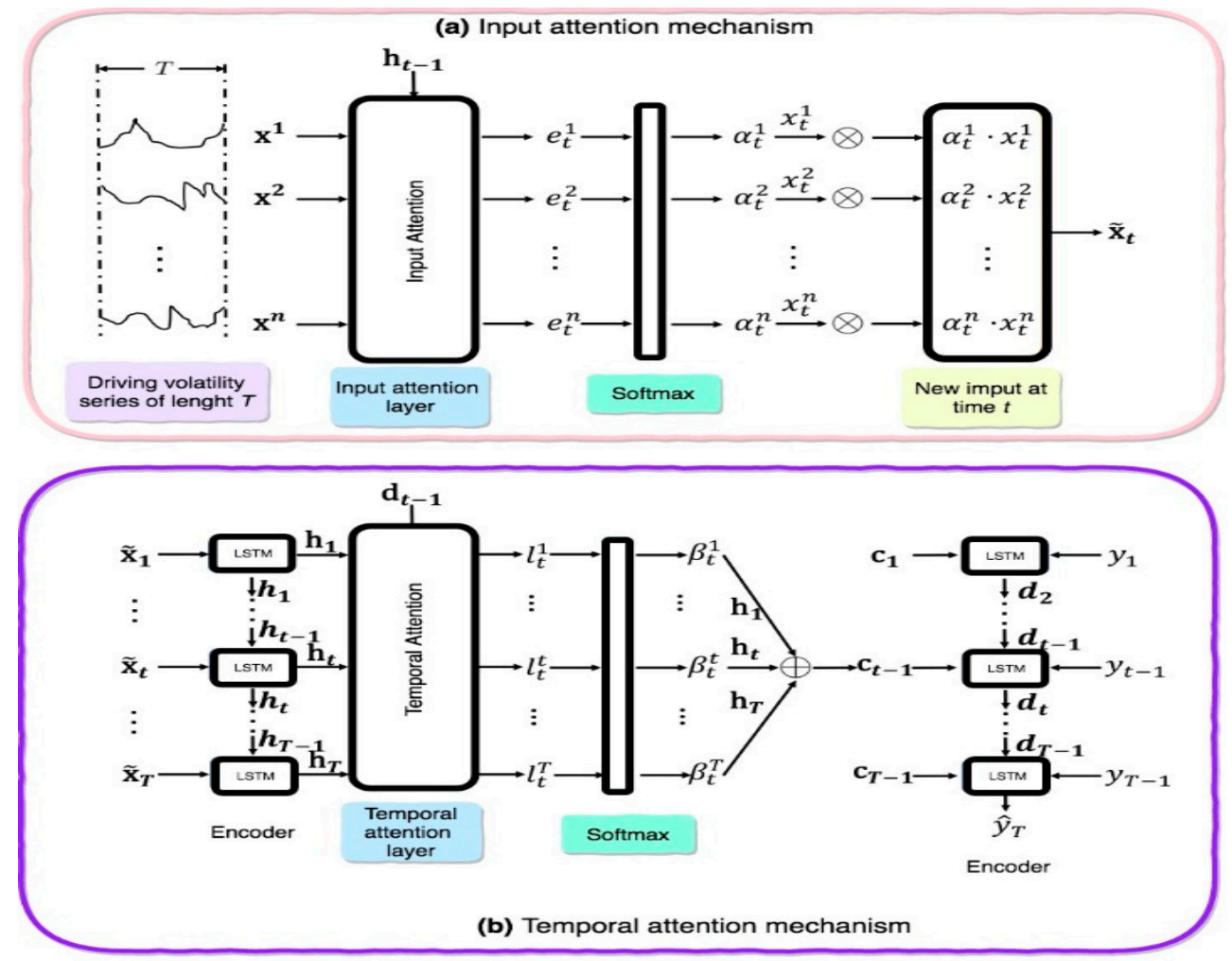

Figure 4. Architecture of the Bi-LSTM with two-stage attention machine learning model. Notes: $x^{1}$, $x^{2}$, and $x^{n}$ represent the volatility series; $h$ is hidden state; $h_{t-1}$ is previous hidden state; $\alpha_{t}^{k}$ is input attention weights; $\widetilde{x}_{t}$ represents newly computed based on the transpose of $\left(\alpha_{t}^{1} x_{t}^{1}, \alpha_{t}^{2} x_{t}^{2}, \ldots, \alpha_{t}^{n} x_{t}^{n}\right)$; $\beta_{t}^{t}$ is temporal attention weight; $d$ is decoder; $d_{t-1}$ represents previous decoder hidden state; and $c_{t}$ is context vector.

The observed volatility series (i.e., $V_{E, k, t}$ series) from Equation (9) are used as the input data for the Bi-LSTM for the two-stage attention machine learning model. Several computations and optimizations regarding the input gate $i_{t}$, forget gate $f_{t}$, and output gate $o_{t}$, and their respective weights, i.e., $W_{i}$ and $b_{i}, W_{f}$ and $b_{f}$, and $W_{o}$ and $b_{o}$, were made. The mathematical expressions of the computations are in line with [50]. The Bi-LSTM with two-stage attention machine learning model learns the inputted $V_{E, k, t}$ series, adjusts the LSTM-based layer outputs with attention, and forecasts the volatile series for a specified number of points. We note that the Bi-LSTM model encapsulates all the year-on-year historical volatilities and uses it to simulate future volatilities.

From Equation (9), the predicted volatility (captured as $y_{v i}$ in Figure 3) for $n$ periods ahead is given by the following:

$$
V_{E, k, j,(t+n)}=\left[V_{E, k, j,(t+n)}-V_{E, k, j,((t+n)-1)}\right] / V_{E, k, j,((t+n)-1)}
$$


where $j$ is the form of volatility (i.e., business as usual, maximum positive, average positive, or minimum positive). From Equation (10), the future value of electricity generated from renewables at the $n$-th period (i.e., $\left.R E G L_{k,(t+n)}\right)$ is computed as follows:

$$
R E G L_{k,(t+n)}=\left[\left(R E G L_{k,((t+n)-1)} * V_{R E G L, k,(t+n)}\right)+\left(R E G L_{k,((t+n)-1)}\right]\right.
$$

where ${ }^{*}$ signifies multiplication.

Several measures were taken to avoid the three pitfalls in machine learning models. These measures include running up to 10 simulations per volatile series and selecting the optimal ones. Other measures include varying the number of layers, size of the layers, epoch, dropout rate, and learning rate. The optimal model we identified after performing the necessary checks has the following parameters: number of layers, 2; the size of a layer, 128; timestamp, 10; epoch, 50; dropout rate, 0.1 ; and learning rate of 0.01 .

Before its implementation, the model was tested and validated on domestic electricity demand data for a ten-year period, i.e., 2010-2019. The 10-year validation period was used to be in line with the literature that considers prediction periods 5 years or longer as long term. The mean absolute percentage error (MAPE) [60], was adopted as a metric to measure the forecast error and the corresponding accuracy was equally computed for the validation period. The forecast errors from adopting the proposed Bi-LSTM model were compared with that from adopting econometric methodology. The heteroscedasticity and autocorrelation-consistent (HAC) models were adopted as the benchmark econometric model.

\section{Results and Discussion}

\subsection{Panel Unit Root and Stationarity Results}

Empirical results from utilizing the five-panel unit test technologies are presented in Table 1. From Table 1, we see that all series in both panels have between five to twelve statistics that are statistically significant at the $5 \%$ or $1 \%$ level. The series $\ln$ GDP for both Egypt-Algeria and Nigeria-South Africa panels records the minimum number of statistically significant metrics and $\operatorname{lnSREGL}$ for the Egypt-Algeria panel with the twelve significant metrics.

Results from Table 1 show that all four series per panel have statistics that are statistically significant at first difference. Such development show that the natural log of domestic electric power consumption, squared levels of electricity generation from renewable sources, total population, and national output variables has no unit root. Thus, $\ln E L C$, $\ln \mathrm{SREGL}, \ln \mathrm{TP}$, and $\ln \mathrm{GDP}$ are stationary at first difference. The recorded stationary series is used to further investigate the possible existence of long-run relationships in each model for both panels.

\subsection{Panel Pedroni Cointegration Results}

Results from applying Pedroni (Engel-Granger-based) cointegration technology on the stationary series are reported in Table 2. From Table 2, only renewable electric power generation for the Egypt-Algeria panel records four statistics that are significant at a 5\% significance level. Despite the statistically significant metrics, four out of eleven statistics fall short of the decision criteria of at least six required to declare the existence of longterm relationship in the REGL model. Thus, the results suggest that there is no long-run relationship between renewable electric power generation and domestic electric power demand, national output, and total population for the Egypt-Algeria panel. 
Table 1. Unit root result.

\begin{tabular}{|c|c|c|c|c|c|}
\hline \multirow{2}{*}{ Variable } & \multirow{2}{*}{ Test } & \multicolumn{2}{|c|}{ Level } & \multicolumn{2}{|c|}{ First Difference } \\
\hline & & I & $\mathrm{I}$ and $\mathrm{T}$ & I & $\mathrm{I}$ and $\mathrm{T}$ \\
\hline \multicolumn{6}{|c|}{ Egypt and Algeria } \\
\hline \multirow{5}{*}{$\ln \mathrm{ELC}$} & $\operatorname{LLC}(t *)$ & $-1.4 *$ & 2.4 & $-3.7^{* * *}$ & $-4.06^{* * *}$ \\
\hline & IPS (W-stat) & 0.48 & 2.59 & $-2.49^{* * *}$ & $-2.9 * * *$ \\
\hline & ADF (Chi-square) & 6.01 & 1.79 & $21.15^{* * *}$ & $19.13^{* * *}$ \\
\hline & PP (Chi-square) & 1.75 & 1.67 & $30.03^{* * *}$ & $26.53^{* * *}$ \\
\hline & Breitung (t-stat) & - & 2.39 & - & 1.1 \\
\hline \multirow{5}{*}{$\ln$ SRELG } & $\operatorname{LLC}\left(\mathrm{t}^{*}\right)$ & -1.01 & $-2.3^{* *}$ & $-9.01^{* * *}$ & $-8.04^{* * *}$ \\
\hline & IPS (W-stat) & -0.15 & -1.27 & $-8.17^{* * *}$ & $-7.53^{* * *}$ \\
\hline & ADF (Chi-square) & 4.18 & 7.14 & $48.32 * * *$ & $40.58^{* * *}$ \\
\hline & PP (Chi-square) & 4 & 6.36 & $61.26^{* * *}$ & $284.65^{* * *}$ \\
\hline & Breitung (t-stat) & - & $-1.81^{* *}$ & - & $-5.59 * * *$ \\
\hline \multirow{5}{*}{$\ln \mathrm{TP}$} & $\operatorname{LLC}\left(t^{*}\right)$ & -1.15 & 17.41 & $-2.02 * *$ & 3.02 \\
\hline & IPS (W-stat) & 0.58 & $-1.76^{* *}$ & $-4.07^{* * *}$ & $-1.71^{* *}$ \\
\hline & ADF (Chi-square) & 3.66 & $9.57^{* *}$ & $23.82 * * *$ & $8.88 *$ \\
\hline & PP (Chi-square) & 0.14 & 0.87 & 5.72 & 3.7 \\
\hline & Breitung (t-stat) & - & 2.29 & - & $-2.54^{* * *}$ \\
\hline \multirow{5}{*}{$\ln \mathrm{GDP}$} & $\operatorname{LLC}\left(t^{*}\right)$ & -0.69 & -0.48 & -0.85 & -0.69 \\
\hline & IPS (W-stat) & 1.68 & -1.16 & $-2.07 * *$ & $-2.2 * *$ \\
\hline & ADF (Chi-square) & 0.73 & 6.75 & $11.43^{* *}$ & $10.98^{* *}$ \\
\hline & PP (Chi-square) & 0.15 & 4.58 & $15.29 * * *$ & $9.26 *$ \\
\hline & Breitung (t-stat) & - & -0.72 & - & $-1.46^{*}$ \\
\hline \multicolumn{6}{|c|}{ Nigeria and South Africa } \\
\hline \multirow{5}{*}{$\ln \mathrm{ELC}$} & $\operatorname{LLC}\left(\mathrm{t}^{*}\right)$ & -1.21 & -0.32 & $-6.13^{* * *}$ & $-5.21^{* * *}$ \\
\hline & IPS (W-stat) & 0.02 & 0.02 & $-5.87^{* * *}$ & $-5.07 * * *$ \\
\hline & ADF (Chi-square) & 3.77 & 4.32 & $33.85^{* * *}$ & $26.91^{* * *}$ \\
\hline & PP (Chi-square) & 4.05 & 1.29 & $33.65^{* * *}$ & $38.58^{* * *}$ \\
\hline & Breitung (t-stat) & - & 0.56 & - & $-5.07^{* * *}$ \\
\hline \multirow{5}{*}{$\operatorname{lnSRELG}$} & $\operatorname{LLC}\left(t^{*}\right)$ & -0.17 & -0.5 & $-7.97^{* * *}$ & $-7^{* * *}$ \\
\hline & IPS (W-stat) & -0.79 & $-1.33 *$ & $-8.13^{* * *}$ & $-7.61^{* * *}$ \\
\hline & ADF (Chi-square) & $8.34 *$ & 7.52 & $48.07^{* * *}$ & $40.97^{* * *}$ \\
\hline & PP (Chi-square) & $8.77 *$ & 7.77 & $48.52 * * *$ & $42.38^{* * *}$ \\
\hline & Breitung (t-stat) & - & -1.12 & - & $-3.07^{* * *}$ \\
\hline \multirow{5}{*}{$\ln \mathrm{TP}$} & $\operatorname{LLC}\left(t^{*}\right)$ & -0.88 & 11.7 & $-2.78^{* * *}$ & -0.25 \\
\hline & IPS (W-stat) & 0.39 & $-1.86^{* *}$ & $-3.16^{* * *}$ & $-1.92 * *$ \\
\hline & ADF (Chi-square) & 0.59 & $9.44 *$ & $18.28^{* * *}$ & $10.09^{* *}$ \\
\hline & PP (Chi-square) & $4.77^{*}$ & $8.79 *$ & 4.13 & 0.71 \\
\hline & Breitung (t-stat) & - & $-2.0^{* *}$ & - & $-2.17 * *$ \\
\hline \multirow{5}{*}{$\ln \mathrm{GDP}$} & $\operatorname{LLC}\left(\mathrm{t}^{*}\right)$ & $-2.3^{* *}$ & 1.87 & $-2.26^{* *}$ & -1.27 \\
\hline & IPS (W-stat) & -0.35 & 0.5 & $-2.04^{* *}$ & 0.25 \\
\hline & ADF (Chi-square) & 3.74 & 1.55 & $10.71^{* *}$ & 3.7 \\
\hline & PP (Chi-square) & 0.3 & 2.02 & $10.51^{* *}$ & 4.97 \\
\hline & Breitung (t-stat) & - & 1.5 & - & 0.24 \\
\hline
\end{tabular}

Note: ${ }^{* * *}$, and ${ }^{* * *}$ signify statistical significance at $10 \%, 5 \%$, and $1 \%$, respectively; I is intercept, and I and T are intercept and trend; all values are rounded to two decimal places. 
Table 2. Pedroni cointegration results.

\begin{tabular}{|c|c|c|c|c|}
\hline \multirow[t]{2}{*}{ Egypt-Algeria Panel } & \multicolumn{4}{|c|}{ Models } \\
\hline & $\operatorname{lnELC}$ & lnSRELG & $\operatorname{lnTP}$ & $\operatorname{lnGDP}$ \\
\hline \multicolumn{5}{|c|}{$\mathrm{H}_{1}$ : common AR coefficients (within-dimension) } \\
\hline Panel v & -1.08 & -0.75 & -0.02 & 0.40 \\
\hline Panel rho & 0.51 & -1.14 & -0.02 & -0.09 \\
\hline Panel PP & 0.08 & $-1.69^{* *}$ & -0.28 & -0.40 \\
\hline Panel ADF & 0.07 & $-1.71 * *$ & -0.14 & -0.08 \\
\hline Panel v (WS) & -1.09 & -0.66 & 0.02 & 0.65 \\
\hline Panel rho (WS) & 0.52 & -0.98 & -0.11 & -0.12 \\
\hline Panel PP (WS) & 0.08 & $-1.55^{*}$ & -0.35 & -0.44 \\
\hline Panel ADF (WS) & 0.07 & $-1.55 *$ & -0.35 & -0.10 \\
\hline \multicolumn{5}{|c|}{$\mathrm{H}_{1}$ : common AR coefficients (between-dimension) } \\
\hline Group rho & 0.91 & -0.49 & 0.53 & 0.40 \\
\hline Group PP & 0.15 & $-1.69 * *$ & -0.01 & -0.29 \\
\hline Group ADF & -1.01 & $-1.68 * *$ & -0.88 & -0.89 \\
\hline \multirow[t]{2}{*}{ Nigeria-South Africa Panel } & \multicolumn{4}{|c|}{ Model } \\
\hline & $\operatorname{lnELC}$ & lnSRELG & $\ln T P$ & $\operatorname{lnGDP}$ \\
\hline \multicolumn{5}{|c|}{$\mathrm{H}_{1}$ : common AR coefficients (within-dimension) } \\
\hline Panel v & -0.38 & 0.12 & 0.80 & 0.77 \\
\hline Panel rho & 0.15 & -0.15 & 0.14 & 0.28 \\
\hline Panel PP & -0.88 & -0.47 & -0.52 & -0.34 \\
\hline Panel ADF & -1.07 & 0.01 & -0.64 & -0.99 \\
\hline Panel v (WS) & -0.39 & 0.39 & 0.87 & 0.61 \\
\hline Panel rho (WS) & 0.15 & -0.31 & 0.16 & 0.32 \\
\hline Panel PP (WS) & -0.91 & -0.67 & -0.37 & -0.21 \\
\hline Panel ADF (WS) & -1.10 & -0.31 & -0.41 & -0.91 \\
\hline \multicolumn{5}{|c|}{$\mathrm{H}_{1}$ : common AR coefficients (between-dimension) } \\
\hline Group rho & 0.88 & 0.18 & 0.89 & 0.98 \\
\hline Group PP & -1.02 & -0.59 & -0.04 & -0.22 \\
\hline Group ADF & -0.72 & -0.09 & 0.15 & -1.01 \\
\hline
\end{tabular}

Note: ${ }^{*}$ and ${ }^{* *}$ signify statistical significance at $10 \%$ and $5 \%$, respectively.

Apart from $\ln$ SREGL model of the Egypt-Algeria panel, results from Table 2 shows that none of the other models recorded statistically significant common AR coefficients (between- and within-dimensions). According to the decision rule on cointegration, the results suggest that there are no cointegrating relationships among the variables for both panels. Thus, in planning long-term domestic electricity demand policies aimed at providing 100\% access to electricity, decision-makers in Egypt, Algeria, Nigeria, and South Africa could ignore the possible contributions from electricity generation from renewables, national output, and total population. The unavailability of long-run relationships means that the vector error correction model cannot be adopted to investigate long-run causal relationships. Though the evidence suggests no long-run relationship exists in models of both panels, there could be short-run causal relations. The vector autoregression (VAR) technique is employed to investigate the possible short-run causalities.

\subsection{Causal Relationships}

Results on short-run causality derived from the VAR models are reported in Table 3. Results from Table 3 show three causal relationships per panel. In the panel of countries with $100 \%$ access to electricity as of 2018, the total population Granger causes renewable electric power generation with feedback effects. The results suggest that countries in such a panel need to consider population and population dynamics in proposing policies that would drive up renewables as a source of electric power generation for domestic consumption. There also exist unidirectional causality running from total population to 
national output. None of the three independent variables were found to cause domestic electricity consumption both in the short- and long-run.

Table 3. Short-run causal relationships.

\begin{tabular}{cccccc}
\hline Model & \multicolumn{7}{c}{ Independent Variable } \\
\hline \multicolumn{7}{c}{ Egypt and Algeria Panel } \\
\hline $\ln$ ELC & $\ln$ SRELG & $\ln$ TP & $\ln$ GDP & ect \\
\hline $\ln$ EREC & - & 0.47 & 0.67 & 0.84 & - \\
$\ln \mathrm{TP}$ & 1.40 & - & $8.22^{* *}$ & 1.32 & - \\
$\ln \mathrm{GDP}$ & 1.99 & $11.97^{* * *}$ & - & $5.37^{*}$ & - \\
\hline \multicolumn{7}{c}{ Nigeria-South Africa Panel } & - & - \\
Model & 0.37 & $4.62^{*}$ & $15.41^{* * *}$ & & ect \\
\hline $\ln \mathrm{ELC}$ & $\ln \mathrm{ELC}$ & $\operatorname{lnSRELG}$ & $\ln \mathrm{TP}$ & $\operatorname{lnGDP}$ & - \\
$\ln \mathrm{SRELG}$ & - & 0.43 & 3.26 & $11.01^{* * *}$ & - \\
$\ln \mathrm{TP}$ & 1.13 & - & 3.94 & 1.04 & - \\
$\ln \mathrm{GDP}$ & 2.65 & $5.74^{* * *}$ & - & $13.11^{* * *}$ & - \\
\hline
\end{tabular}

Note: ${ }^{*}, *$, and ${ }^{* * *}$ denote significance at $10 \%, 5 \%$, and $1 \%$ level, respectively; all values are rounded to two decimal places.

For the panel of countries that are yet to fulfill the targets of providing electricity for all, the results suggest the existence of three short-run unidirectional relationships. These causal relationships are from national output to domestic electricity consumption, national output to population, and electricity consumption to the total population. This is in line with works by Akinwale and Jesule [61], who found that there is unidirectional causality from real GDP to electricity consumption. Furthermore, similar studies by Ali et al. [62], Akinyemi [63], Omisakin and Olusegun [64], and Nnaji et al. [65] found a unidirectional causality from urbanization to electricity consumption and economic growth. This is also similar to the findings of our study and supports the proposition that GDP impacts electricity consumption.

The causal relationship running from national output to electricity consumption for the Nigeria-South Africa panel is in reverse to the findings by Aktas [66], which reports that there exists a causal relationship between the two variables, but it runs from electricity consumption to national output. The short-run unidirectional causal relationship running from $\ln G D P$ to $\ln$ ELC for the Nigeria-South Africa panel shows that decision-makers in the two countries need to consider and assess the impacts of policies geared towards improving access to electricity on the macroeconomy and minimize potential adverse effects on the growth of national output. It is evident from the causal relationships that renewable electric power generation does not cause domestic electricity consumption in both models. This is due to the historical trends of exceedingly low generation from renewables-particularly solar and wind. Enerdata reports that electricity generation from solar and wind accounted for $0.77 \%, 3 \%, 0.09 \%$, and, $4 \%$ for Algeria, Egypt, Nigeria, and South Africa, respectively. Such minuscule supply levels rarely impact total domestic demand and transforming the existing fossil-fuel-driven electric power system into complete renewables requires radical innovations in renewable electric power generations.

\subsection{Variance Decomposition of Radical Renewable Electric Power Generation}

Estimates of the radical renewable electric power innovations and contributions from the other three sampled variables required to achieve the targeted innovations are reported in Table 4. Results from utilizing the Cholesky decomposition factorization methodology variance decomposition, with estimations obtained through Monte Carlo (with 100 repetitions), as depicted in Table 4, show that a greater proportion of the innovations must be from within REGL, i.e., within the renewable electric power generation itself. 
Table 4. Variance decomposition of renewable electric power generation.

\begin{tabular}{cccccc}
\hline Panel & Period & $\operatorname{lnSRELP}$ & $\ln$ ELC & $\ln$ TP & $\ln$ GDP \\
\hline \multirow{2}{*}{ Egypt-Algeria } & 1 & 100.00 & 0.00 & 0.00 & 0.00 \\
& 3 & 99.41 & 0.00 & 0.33 & 0.26 \\
& 5 & 98.32 & 0.00 & 0.93 & 0.74 \\
& 7 & 97.10 & 0.01 & 1.60 & 1.29 \\
Nigeria-South Africa & 9 & 95.87 & 0.04 & 2.25 & 1.84 \\
& 11 & 94.66 & 0.09 & 2.86 & 2.39 \\
\hline & 1 & 100.00 & 0.00 & 0.00 & 0.00 \\
& 3 & 98.84 & 0.40 & 0.03 & 0.72 \\
& 7 & 97.26 & 0.86 & 0.08 & 1.80 \\
& 9 & 95.95 & 1.16 & 0.11 & 2.78 \\
& 11 & 94.98 & 1.28 & 0.14 & 3.59 \\
& 94.30 & 1.30 & 0.16 & 4.23 \\
\hline
\end{tabular}

For the already fully electrified Egypt-Algeria panel, contributions and innovations of $\sim 100 \%$ in year $1, \sim 97 \%$ by year 7 , and $\sim 94 \%$ by year 11 internal to REGL are required to achieve ambitious and radically set policies or targets of transitioning to green, sustainable and affordable electric power system by 2030 . The trends observed in intra-renewable electric power innovations are similar in the Nigeria-South Africa panel; both panels record high but decreasing Intra-REGL contributions but the decrease in contributory innovations in REGL is sharper in the Nigeria-South Africa than the Egypt-Algeria panel. Evidence from Table 4 suggests that innovations in domestic electric power consumption, total population, and national output would also help achieve the REGL targets and the contributions of the three variables are similar yet vary to some degree per panel. One similarity is that the contributions from domestic electric power demand, population, and national output increase from year 1 through to 11, but the magnitude of the increment varies per panel. For instance, contributions through innovations in domestic electric power demand increase from $0 \%$ in year 1 to $1.30 \%$ in year 11 for the Nigeria-South Africa panel, but the contribution of the same variable increases from $0 \%$ to $0.09 \%$ in the same timeline for the Egypt-Algeria panel. The variations in contributory innovations observed per panel can be ascribed to the varied access to electricity and the corresponding volatility in the existing electric power system. Hence, considering the volatility in the existing renewable electric power generation system, the provision of volatility-induced outlooks would be instrumental for decision-makers to make informed and viable decisions.

\subsection{Volatility-Dependent Future Renewable Electric Power Generation Trends}

Results of the computed year-on-year volatilities in renewable electric power generation and depicted in Figure 5. From Figure 5, Algeria has the most volatile renewable electricity system in the past three decades with maximum volatility of $\sim 365 \%$. The high volatility can be good for Algeria as the results suggest that the country can increase renewable electric power by more than three-fold the supply level of a given referenced year. Results from the maximum year-on-year volatility show that, based on historical justifications, the four countries can increase electric power generated from renewable sources in a given year by $\sim 41 \%$ (the level of the previous year) for Nigeria, $\sim 100 \%$ for South Africa, $21 \%$ for Egypt, and more than $300 \%$ for Algeria.

The Bi-LSTM with the two-stage attention model proposed in Table 5, performed significantly better when applied to the volatile series than the benchmark econometric HAC model. For instance, in using year-on-year volatility series on Egypt covering 1991-2009 to propose pathways for domestic electric power consumption for the 2010-2019 period, the proposed machine learning model records a MAPE of 4.02 which presents an improvement of $\sim 2$-fold from the HAC-based results. The year-on-year forecast error of the machine learning model for the referenced 2019 period is $3.78 \%$ and $6.32 \%$ for the HAC case. This represents an improvement of $\sim 5$-fold relative to the benchmark econometric model. Based 
on the observed high precision recorded, the Bi-LSTM attention-driven machine learning model is implemented for volatility-induced forecasting and transition pathways for the 2020-2030 period for each of the four sampled countries. Results of the corresponding projections and pathways are presented in Table 5 and observed values for all 10 simulations per volatile series.
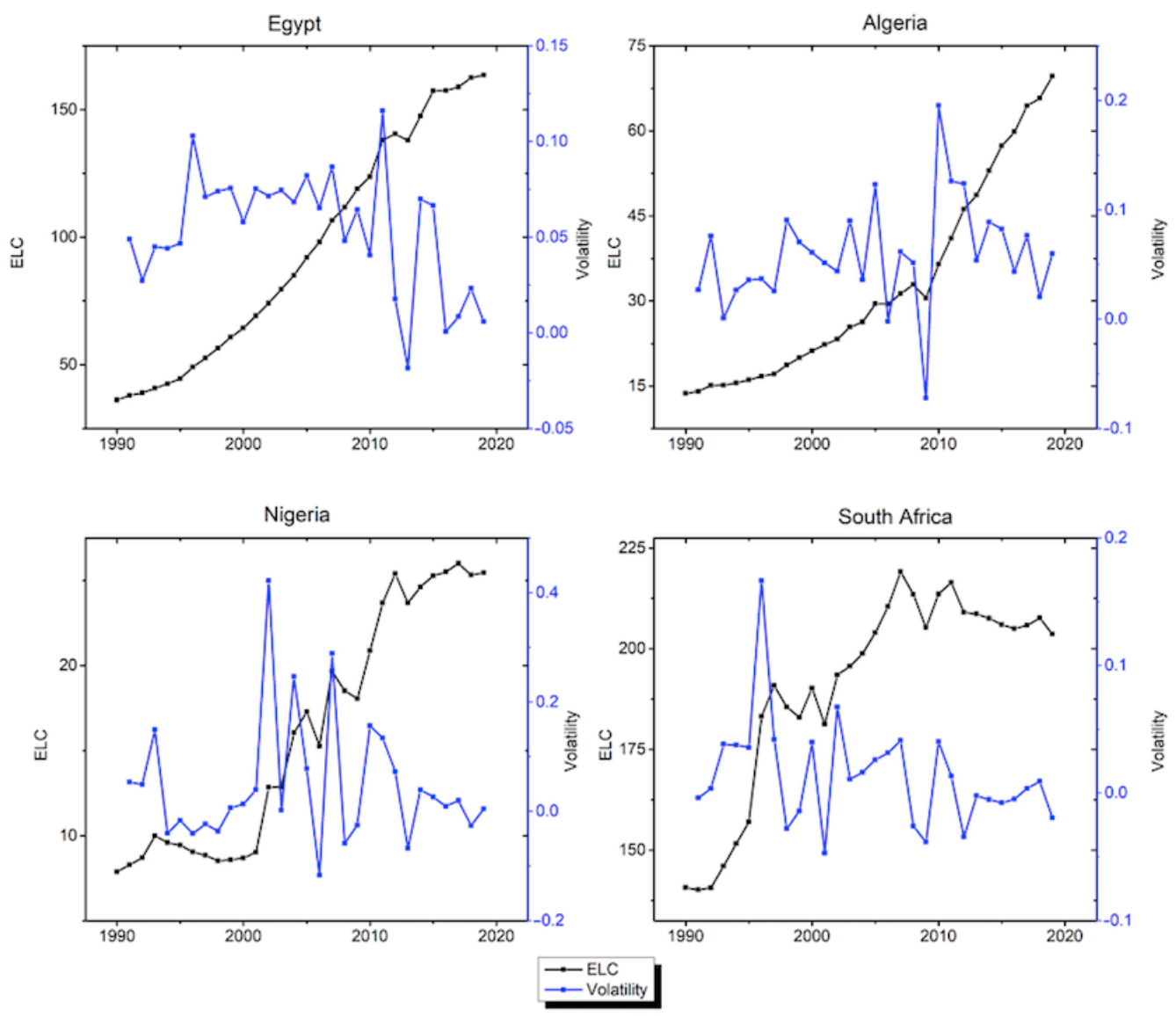

Figure 5. Observed domestic electric power consumption and related year-on-year volatility. ELC represents domestic electricity consumption and is measured in TWh.

Facts from Enerdata's Global Statistical Yearbook 2020 report puts total domestic electric power consumption (in TWh) in 2019 at $~ 70$ for Algeria, 163 for Egypt, 25 for Nigeria, and $\sim 204$ for South Africa. Noting that electric power conservation is equally an important factor to achieving the target of providing green and sustainable electric power for all, deducing from historical volatility rates in domestic demand could help provide conservative-induced estimates of domestic electric power consumption for each country. The conservation-driven projections of electricity demand are comparable to the 'ELC (BAU forecast, min)' representations in Table 5. The conservative-induced projections are based on the minimum positive year-on-year volatility learned from the volatile series of the 1990-2019 period. If conservative practices are implemented, domestic electricpower consumption in 2030 is projected to reach $\sim 220, \sim 116, \sim 34$, and 206 TWh for Egypt, Algeria, Nigeria, and South Africa, respectively. The rise (relative to 2019 levels) in electricity demand is in line with existing projections but the magnitude of the increment varies widely. For instance, in South Africa, the integrated Resource Plan (IRP) 2016 projects electricity consumption for South Africa to reach 350 TWh in 2030 [67], and the Council for Scientific and Industrial Research (CSIR) [67] estimates it (in TWh) to be between $\sim 284$ and 332. Both projections are significantly higher than the $206-259$ TWh derived from adopting the machine learning model proposed in this study. Projections based on the maximum positive year-on-year volatility, represented as 'ELC (BAU forecast, min)' in 
Table 5, puts domestic electricity demand for the four countries considerably higher than the 'ELC (BAU forecast, min)' estimates. On the basis that conservative demand practices for electricity are preferred, the 'ELC (BAU forecast, min)' estimates are used for further discussions. Results on renewable electric power generation from the business as usual (i.e., RELG (BAU forecast, max)) and minimum positive volatility (i.e., RELG (minimum volatility, max)) show an increase in a generation, but not significant enough to achieve REGL-dominant electric power system by 2030. Rather, evidence from the maximum positive volatility (i.e., RELG (maximum volatility, max)) shows that $100 \%$ access to green and sustainable electricity is achievable for Algeria, Nigeria, and South Africa by 2030.

Table 5. Projected electric power demand and volatility-driven renewable generation roadmaps.

\begin{tabular}{|c|c|c|c|}
\hline Country, Scenario, and Pathway & 2020 & 2025 & 2030 \\
\hline \multicolumn{4}{|c|}{ Egypt } \\
\hline ELC (BAU forecast, min) & 167.98 & 187.94 & 220.17 \\
\hline ELC (BAU forecast, max) & 174.53 & 221.88 & 319.31 \\
\hline RELG (BAU forecast, max) & 20.35 & 27.48 & 29.9 \\
\hline RELG (minimum volatility, max) & 19.58 & 22.72 & 26.76 \\
\hline RELG (maximum volatility, max) & 23.57 & 57.41 & 154.25 \\
\hline \multicolumn{4}{|c|}{ Algeria } \\
\hline ELC (BAU forecast, min) & 72.26 & 90.76 & 115.85 \\
\hline ELC (BAU forecast, max) & 75.28 & 107.29 & 139.03 \\
\hline RELG (BAU forecast, max) & 1.17 & 7.72 & 66.47 \\
\hline RELG (minimum volatility, max) & 0.86 & 3.41 & 18.03 \\
\hline RELG (maximum volatility, max) & 3.86 & $>200$ & $>200$ \\
\hline \multicolumn{4}{|c|}{ Nigeria } \\
\hline ELC (BAU forecast, min) & 22.86 & 28.81 & 33.7 \\
\hline ELC (BAU forecast, max) & 27.87 & 39.53 & 56.37 \\
\hline RELG (BAU forecast, max) & 6.89 & 8.5 & 10.88 \\
\hline RELG (minimum volatility, max) & 6.41 & 7.11 & 10.17 \\
\hline RELG (maximum volatility, max) & 9.02 & $>50.0$ & $>50.0$ \\
\hline \multicolumn{4}{|c|}{ South Africa } \\
\hline ELC (BAU forecast, min) & 203.67 & 201.67 & 205.84 \\
\hline ELC (BAU forecast, max) & 208.99 & 231.5 & 258.8 \\
\hline RELG (BAU forecast, $\max$ ) & 18.52 & 33.13 & 49.48 \\
\hline RELG (minimum volatility, max) & 16.6 & 27.04 & 54.34 \\
\hline RELG (maximum volatility, max) & 32.54 & 297.72 & $>300$ \\
\hline
\end{tabular}

Note: BAU is business as usual; all values are in TWh.

From Table 5, REGL outlooks for 2030 from the maximum radical renewable electric power innovation pathways depicted indicate projected electric power generation from renewables for the three countries significantly outweigh the expected caps in domestic consumption in 2030. That is, following the historical renewable-electricity innovation within the three countries, the three nations can provide green and sustainable electric power to all people living in these countries within the next decade. Though renewableelectricity generation for each country is projected to rise, projections from this study are significantly different from existing outlooks. For instance, for Nigeria, the renewable electric power generation projections based on the volatility learned is vastly different from estimates reported by the International Energy Agency (IEA). The IEA projects that in 2030, electricity generations from renewables (i.e., hydro, solar, and bioenergy) would reach $31 \mathrm{TWh}$ [68], which is significantly larger from our BAU projection (i.e., 10.88 TWh), but notably less than levels of generation from the maximum positive volatility transition pathway (i.e., more than $50 \mathrm{TWh}$ ). Results from the IEA projections show that Nigeria cannot achieve 100\% access to renewable electric power, but that of the machine learning model proposed herein show that such target is achievable. The finding that radical renewable electric power innovation can help Nigeria generate $100 \%$ of domestic electricity needs, which translates into zero greenhouse gas emissions from the electric power sector, 
is in line with the findings of Ameyaw et al. [69], who report that zero fossil fuel carbon dioxide emissions are achievable for Nigeria by 2030.

Relative to the other three countries, Egypt is less likely to achieve $100 \%$ access to green electric power by 2030 unless tougher renewable policies are implemented. Although Egypt is less likely to achieve its target in the absence of tougher policies, the country could make giant strides in renewable electric power systems as the $\sim 154$ TWh expected in 2030 represents an increase in current (i.e., 2019) REGL contribution by $\sim 800 \%$. The approximately 8 -fold increase in renewable electric power production means that power producers in Egypt can supply a greater proportion of demand by people and firms in the country from solar, wind, geothermal, and hydro sources. It must be noted that the finding of Algeria, Nigeria, and South Africa achieving 100\% access to electricity generated from renewable sources and Egypt's renewable electric power-dominant electricity system by 2030 would be viable and sustainable if electricity generation from solar and wind (due to the continual decrease in their Levelized costs) dominated the supply mix.

\section{Conclusions and Policy Implications}

Transforming the electric power sector to the dominant renewable electric power mix is pivotal to achieving electricity-related aspects of Sustainable Development Goal 7. Countries in Africa, including top electric-power-generating/consuming nations, have made some progress in fulfilling the electric power demands of the population with supply from solar, wind, hydro, and geothermal. The advent of the coronavirus pandemic is expected to derail and stagnate the transition to $100 \%$ renewable electric power systems. Currently, the electric power systems of the top four energy-consuming African countries, namely Egypt, Algeria, Nigeria, and South Africa, are heavily dependent on fossil fuels. Hence, radical renewable electricity generation innovations are required in the post-2020Covid-19 pandemic era to achieve the aching objective of providing affordable and green electricity to $100 \%$ of a country's population, i.e., domestic consumption, preferably by 2030. In their quest to provide affordable, green, and sustainable electric power for all, uncovering the determinants of domestic electric power demand would help decisionmakers in top electricity-consuming African countries make informed decisions, as well as draft and implement viable and sustainable policies.

The determinants of domestic electricity demand in the top-four electricity-consuming African countries vary according to the percentage of the current population with access to electricity and volatility in a country's renewable electric power system, but there is rare evidence of scientific research that leverage on the observed disparities in access to electricity to investigate the long- and short-run determinants of domestic electricpower demand. Added, renewable electricity innovations and viable volatility-consistent roadmaps are required for cost-minimizing transition but such research is very rare. This study investigated the impacts of radical renewable electric power production innovations and macroeconomics indicators on domestic electricity demand for panels of countries that currently supply electricity to $100 \%$ of their population (i.e., Egypt and Algeria) and countries that currently supply electricity to less than $100 \%$ of their population (i.e., Nigeria and South Africa). We recorded only short-run causal relationships, which mean that decision-makers in both panels of nations can achieve the objective of providing green, affordable, and sustainable electricity to $100 \%$ of their respective population through a series on linked short-run policy planning. Evidence from a volatility-induced outlook suggests that each of the four countries can achieve the electric power-related periphery of SDG7 through innovations in and utilization of electricity generation from solar and wind. Thus, though the coronavirus has caused and could keep causing disturbances in renewable electric power generation, the empirical evidence suggests that the countries can still transition to $100 \%$ access to renewable and affordable electric power by 2030 . One limitation of this study is that it focuses on the top four electric-power-consuming nations in the African region, leaving 50 other African countries untouched. Future researchers can research the other 50 African nations. 
Author Contributions: Formal analysis, M.A.-S.; Investigation, Y.S.; Methodology, Y.S.; Project administration, M.A.-S.; Software, O.A.; Writing-original draft, M.A.-S. and A.M.; Writing-review \& editing, M.A.-S.; Y.S.; O.A. and A.M. All authors have read and agreed to the published version of the manuscript.

Funding: This research received no funding.

Institutional Review Board Statement: Not applicable.

Informed Consent Statement: Not applicable.

Data Availability Statement: Not applicable.

Conflicts of Interest: Authors declare no conflict of interest.

\section{References}

1. Churchill, S.A.; Ivanovski, K. Electricity consumption and economic growth across Australian states and territories. Appl. Econ. 2020, 52, 866-878. [CrossRef]

2. Liu, D.; Zeng, X.; Su, B.; Wang, W.; Sun, K.; Sadia, U.H. A social network analysis regarding electricity consumption and economic growth in China. J. Clean. Prod. 2020, 274, 122973. [CrossRef]

3. Li, F.; Xie, J.; Wang, W. Incentivizing sustainable development: The impact of a recent policy reform on electricity production efficiency in China. Sustain. Dev. 2019, 27, 770-780. [CrossRef]

4. Akadiri, S.S.; Alola, A.A.; Olasehinde-Williams, G.; Etokakpan, M.U. The role of electricity consumption, globalization and economic growth in carbon dioxide emissions and its implications for environmental sustainability targets. Sci. Total Environ. 2020, 708, 134653. [CrossRef]

5. Mazorra, J.; Sánchez-Jacob, E.; de la Sota, C.; Fernández, L.; Lumbreras, J. A comprehensive analysis of cooking solutions co-benefits at household level: Healthy lives and well-being, gender and climate change. Sci. Total Environ. 2020, 707, 135968. [CrossRef]

6. Sarkodie, S.A.; Adams, S. Electricity access, human development index, governance and income inequality in Sub-Saharan Africa. Energy Rep. 2020, 6, 455-466. [CrossRef]

7. Schaubroeck, T. SDGs: Aggregate to fix prioritization. Nature 2020, 584, 334. [CrossRef]

8. Irwin, B.R.; Hoxha, K.; Grépin, K.A. Conceptualising the effect of access to electricity on health in low- and middle-income countries: A systematic review. Glob. Public Health 2020, 15, 452-473. [CrossRef]

9. Nock, D.; Levin, T.; Baker, E. Changing the policy paradigm: A benefit maximization approach to electricity planning in developing countries. Appl. Energy 2020, 264, 114583. [CrossRef]

10. World Bank Access to Electricity (\% of Population)—Sub-Saharan Africa. Available online: https://data.worldbank.org/indicator (accessed on 15 January 2020).

11. Naidoo, R.; Fisher, B. Sustainable Development Goals: Pandemic reset. Nature 2020, 583, 198-201. [CrossRef]

12. Enerdata Global Energy Trends 2020-Update. Available online: https:/ / yearbook.enerdata.net/ (accessed on 2 January 2019).

13. World Development Indicators. Available online: https://yearbook.enerdata.net/total-energy/world-consumption-statistics. html (accessed on 2 January 2019).

14. Bohlmann, J.A.; Inglesi-Lotz, R. Examin ing the determinants of electricity demand by South African households per income level. Energy Policy 2021, 148, 111901. [CrossRef]

15. Kayalica, M.O.; Ozozen, A.; Guven, D.; Kayakutlu, G.; Bayar, A.A. Electricity consumption analysis based on Turkish Household Budget Surveys. Energy Ecol. Environ. 2020, 5, 444-455. [CrossRef]

16. Kim, M.J. Understanding the determinants on household electricity consumption in Korea: OLS regression and quantile regression. Electr. J. 2020, 33, 106802. [CrossRef]

17. Kostakis, I. Socio-demographic determinants of household electricity consumption: Evidence from Greece using quantile regression analysis. Curr. Res. Environ. Sustain. 2020, 1, 23-30. [CrossRef]

18. Đurišić, V.; Rogić, S.; Smolović, J.C.; Radonjić, M. Determinants of household electrical energy consumption: Evidences and suggestions with application to Montenegro. Energy Rep. 2020, 6, 209-217. [CrossRef]

19. Sherwin, E.D.; Henrion, M.; Azevedo, I.M.L. Estimation of the year-on-year volatility and the unpredictability of the United States energy system. Nat. Energy 2018, 3, 341-346. [CrossRef]

20. Kraan, O.; Chappin, E.; Kramer, G.J.; Nikolic, I. The influence of the energy transition on the significance of key energy metrics. Renew. Sustain. Energy Rev. 2019, 111, 215-223. [CrossRef]

21. Mofijur, M.; Fattah, I.M.R.; Alam, M.A.; Islam, A.B.M.S.; Ong, H.C.; Rahman, S.M.A.; Najafi, G.; Ahmed, S.F.; Uddin, M.A.; Mahlia, T.M.I. Impact of COVID-19 on the social, economic, environmental and energy domains: Lessons learnt from a global pandemic. Sustain. Prod. Consum. 2021, 26, 343-359. [CrossRef]

22. Anonymous. Time to revise the Sustainable Development Goals. Nature 2020, 583, 331-332. [CrossRef] [PubMed]

23. Sachs, J.; Schmidt-Traub, G.; Lafortune, G. SDGs: Affordable and more essential now. Nature 2020, 584, 344. [CrossRef]

24. Xu, Y.; Ramanathan, V.; Victor, D.G. Global warming will happen faster than we think. Nature 2018, 564, 30-32. [CrossRef] 
25. Rogelj, J.; Popp, A.; Calvin, K.V.; Luderer, G.; Emmerling, J.; Gernaat, D.; Fujimori, S.; Strefler, J.; Hasegawa, T.; Marangoni, G.; et al. Scenarios towards limiting global mean temperature increase below $1.5^{\circ} \mathrm{C}$. Nat. Clim. Chang. 2018, 8, 325-332. [CrossRef]

26. Rogelj, J.; den Elzen, M.; Höhne, N.; Fransen, T.; Fekete, H.; Winkler, H.; Schaeffer, R.; Sha, F.; Riahi, K.; Meinshausen, M. Paris Agreement climate proposals need a boost to keep warming well below $2{ }^{\circ} \mathrm{C}$. Nature 2016, 534, 631-639. [CrossRef]

27. Goreau, T.J.; Hayes, R.L. Global warming triggers coral reef bleaching tipping point. Ambio 2021, 50, 1137-1140. [CrossRef]

28. Feng, G.F.; Yang, H.C.; Gong, Q.; Chang, C.-P. What is the exchange rate volatility response to COVID-19 and government interventions? Econ. Anal. Policy 2021, 69, 705-719. [CrossRef]

29. Ertuğrul, H.M.; Güngör, B.O.; Soytas, U. The Effect of the COVID-19 Outbreak on the Turkish Diesel Consumption Volatility Dynamics Consumption Volatility Dynamics. Energy Res. Lett. 2020, 1, 1-4.

30. Tenenbaum, B.; Greacen, C.; Siyambalapitiya, T.; Knuckles, J. From the Bottom Up: How Small Power Producers and Mini-Grids Can Deliver Electrification and Renewable Energy in Africa. 2014. Available online: https://elibrary.worldbank.org/doi/abs/10 .1596/978-1-4648-0093-1 (accessed on 27 March 2014).

31. Tang, C.F.; Tan, B.W.; Ozturk, I. Energy consumption and economic growth in Vietnam. Renew. Sustain. Energy Rev. 2016, 54, 1506-1514. [CrossRef]

32. Fawcett, A.A.; Iyer, G.C.; Clarke, L.E.; Edmonds, J.A.; Hultman, N.E.; McJeon, H.C.; Rogelj, J.; Schuler, R.; Alsalam, J.; Asrar, G.R.; et al. Can Paris pledges avert severe climate change? Science 2015, 350, 1168-1169. [CrossRef]

33. Khan, M.K.; Khan, M.I.; Rehan, M. The relationship between energy consumption, economic growth and carbon dioxide emissions in Pakistan. Financ. Innov. 2020, 6, 1-13. [CrossRef]

34. Chidiezie, M.E.T. Political will and collaboration for electric power reform through renewable energy in Africa. Energy Policy 2010, 38, 678-684.

35. Egyptian Government. The Arab Republic of Egypt Intended Nationally Determined Contributions as per United Nation Framework Convention on Climate Change. Available online: https://www4.unfccc.int/sites/ndcstaging/PublishedDocuments/ Egypt\%20First/Egyptian\%20INDC.pdf (accessed on 10 February 2019).

36. Shobana, G.; Umamaheswari, K. Forecasting by Machine Learning Techniques and Econometrics. In Proceedings of the IEEE 2021 6th International Conference on Inventive Computation Technologies (ICICT), Coimbatore, India, 20-22 January 2021; pp. 1010-1016.

37. Aghahosseini, A.; Bogdanov, D.; Breyer, C. Towards sustainable development in the MENA region: Analysing the feasibility of a $100 \%$ renewable electricity system in 2030. Energy Strategy Rev. 2020, 28, 100466. [CrossRef]

38. UNFCCC. Nigeria's Intended National Determined Contribution. 2015. Available online: https://papers.ssrn.com/sol3/papers. cfm?abstract_id=2843279 (accessed on 10 February 2016).

39. Apergis, N.; Payne, J.E. Renewable energy consumption and growth in Eurasia. Energy Econ. 2010, 32, 1392-1397. [CrossRef]

40. Agyei-Sakyi, M. Data on Electric Power for Selected African Countries. Mendely Data, 2021. Available online: https://data. mendeley.com/datasets/mv3pd64y86/1 (accessed on 21 May 2021).

41. Valadkhani, A.; Nguyen, J.; Bowden, M. Pathways to reduce $\mathrm{CO}_{2}$ emissions as countries proceed through stages of economic development. Energy Policy 2019, 129, 268-278. [CrossRef]

42. Brecha, R. Electricity Access Threshold for Meeting Non-Energy SDG Targets. Eur. J. Sustain. Dev. 2019, 8, 90-100. [CrossRef]

43. Lin, B.; Li, Z. Is more use of electricity leading to less carbon emission growth? An analysis with a panel threshold model. Energy Policy 2020, 137, 111121. [CrossRef]

44. Gujarati, D.N. Basic Econometrics; McGraw-Hill: New York, NY, USA, 2004; ISBN 0072427922.

45. Levin, A.; Lin, C.; Chu, C.-S.J. Unit root tests in panel data: Asymptotic and finite-sample properties. J. Econ. 2002, 108, 1-24. [CrossRef]

46. Im, S.K.; Pesaran, M.H.; Shin, Y. Testing for unit roots in heterogeneous panels. J. Econ. 2003, 115, 53-74. [CrossRef]

47. Maddala, G.S.; Wu, S. A Comparative Study of Unit Root Tests with Panel Data and a New Simple Test. Oxf. Bull. Econ. Stat. 1999, 61, 631-652. [CrossRef]

48. Choi, I. Unit root tests for panel data. J. Int. Money Financ. 2001, 20, 249-272. [CrossRef]

49. Hadri, K. Testing for stationarity in heterogeneous panel data. Econ. J. 2000, 3, 148-161. [CrossRef]

50. Breitung, J. The Local Power of Some Unit Root Tests for Panel Data. In Advances in Econometrics; JAI Press: Amsterdam, The Netherlands, 2000; pp. 161-178.

51. Wang, S.; Li, G.; Fang, C. Urbanization, economic growth, energy consumption, and $\mathrm{CO}_{2}$ emissions: Empirical evidence from countries with different income levels. Renew. Sustain. Energy Rev. 2018, 81, 2144-2159. [CrossRef]

52. Oppong, A.; Jie, M.; Acheampong, K.N.; Sakyi, M.A. Variations in the environment, energy and macroeconomic interdependencies and related renewable energy transition policies based on sensitive categorization of countries in Africa. J. Clean. Prod. 2020, 255, 119777. [CrossRef]

53. Agyeman, J.K.; Ameyaw, B.; Li, Y.; Appiah-Kubi, J.; Annan, A.; Oppong, A.; Twumasi, M.A. Modeling the long-run drivers of total renewable energy consumption: Evidence from top five heavily polluted countries. J. Clean. Prod. 2020, $277,123292$. [CrossRef]

54. Pedroni, P. Panel Cointegration: Asymptotic and Finite Sample Properties of Pooled Time Series Tests with an Application to the PPP Hypothesis. Econ. Theory 2004, 20, 597-625. [CrossRef] 
55. Pedroni, P. Critical Values for Cointegration Tests in Heterogeneous Panels with Multiple Regressors. Oxf. Bull. Econ. Stat. 1999, 61, 653-670. [CrossRef]

56. Ters, K.; Urban, J. Estimating unknown arbitrage costs: Evidence from a 3-regime threshold vector error correction model. J. Financ. Mark. 2020, 47, 1-14. [CrossRef]

57. Caruso, G.; Colantonio, E.; Gattone, S.A. Relationships between renewable energy consumption, social factors, and health: A panel vector auto regression analysis of a cluster of 12 EU countries. Sustainability 2020, 12, 2915. [CrossRef]

58. Sohl, T.; Vroom, G.; Fitza, M.A. How Much Does Business Model Matter for Firm Performance? A Variance Decomposition Analysis. Acad. Manag. Discov. 2020, 6, 61-80. [CrossRef]

59. Jie, M.; Oppong, A.; Acheampong, K.N.; Abruquah, L.A. Forecasting Renewable Energy Consumption under zero assumptions. Sustainability 2018, 10, 576. [CrossRef]

60. Yang, Y.; Wu, B.; Zhao, K.; Guo, W. Tweet stance detection: A two-stage DC-BILSTM model based on semantic attention. In Proceedings of the 2020 IEEE 5th International Conference on Data Science in Cyberspace (DSC), Hong Kong, China, 27-30 July 2020; pp. 22-29.

61. Akinwale, Y.; Jesuleye, O.; Siyanbola, W. Empirical Analysis of the Causal Relationship Between Electricity Consumption and Economic Growth in Nigeria. J. Econ. Manag. Trade 2013, 3, 277-295. [CrossRef]

62. Ali, H.S.; Nathaniel, S.P.; Uzuner, G.; Bekun, F.V.; Sarkodie, S.A. Trivariate modelling of the nexus between electricity consumption, urbanization and economic growth in Nigeria: Fresh insights from Maki Cointegration and causality tests. Heliyon 2020, 6, e03400. [CrossRef] [PubMed]

63. Akinyemi, O.; Alege, P.O.; Ogundipe, A.; Osabuohien, E. Energy security and the green growth Agenda in Africa. In Proceedings of the 2nd International Conference on Africa Development Issue, Ota, Nigeria, 11-13 May 2015.

64. Omisakin, D.; Olusegun, A. Energy consumption and economic growth in Nigeria: A bounds testing cointegration approach. J. Econ. Theory 2008, 2, 118-123.

65. Nnaji, C.E.; Chukwu, J.O.; Nnaji, M. Electricity Supply, Fossil fuel Consumption, $\mathrm{CO}_{2}$ Emissions and Economic Growth: Implications and Policy Options for Sustainable Development in Nigeria. Int. J. Energy Econ. Policy 2013, 3, 262.

66. Get.Invest. South Africa: Energy Sector. Available online: https://www.get-invest.eu/market-information/south-africa/energysector/ (accessed on 5 December 2020).

67. Energy Department Forecasts for Electricity Demand in South Africa (2017-2050) Using the CSIR Sectoral Regression Model for the Integrated Resource Plan of South Africa. Available online: http:/ / www.energy.gov.za/IRP/irp-update-draft-report2018/ CSIR-annual-elec-demand-forecasts-IRP-2015.pdf (accessed on 5 November 2020).

68. IEA. Nigeria Electricity Generation by Technology in the Africa Case, 2010-2040. Available online: https://www.iea.org/dataand-statistics / charts/nigeria-electricity-generation-by-technology-in-the-africa-case-2010-2040 (accessed on 5 November 2020).

69. Ameyaw, B.; Yao, L.; Oppong, A.; Agyeman, J.K. Investigating, forecasting and proposing emission mitigation pathways for $\mathrm{CO}_{2}$ emissions from fossil fuel combustion only: A case study of selected countries. Energy Policy 2019, 130, 7-21. [CrossRef] 